\title{
Common Fixed Point Theorem in 2-Menger Space via (S-B) Property
}

\author{
Geetanjali Sharma ${ }^{1} \quad$ Richa Gupta $^{2} \quad$ Pankaj Tiwari $^{3} \quad$ Akshay Sharma $^{2}$ \\ 1.Research Scholar, Sarvepalli Radhakrishnan University, Bhopal (M.P.), India \\ 2.Faculty of Science, Sarvepalli Radhakrishnan University, Bhopal (M.P.), India \\ 3.Dept. of Mathematics, Govt. Naveen College, Lidhoura, Tikamgarh (M.P.), India
}

\begin{abstract}
In this paper, first we prove a common fixed point theorem using weakly compatible mapping in 2- Menger space which generalize the well known results. Secondly, we prove a common fixed point theorem using (S-B) property along with weakly compatible maps. (S-B) property defined by Sharma and Bamoria [16] via implicit relation.

Keywords: Common fixed points, Metric space, S-B property, 2-Menger space, weakly compatible mapping and implicit relation.
\end{abstract}

AMS subject classification- $47 \mathrm{H} 10,54 \mathrm{H} 25$.

DOI: $10.7176 / \mathrm{MTM} / 9-5-01$

Publication date:May $31^{\text {st }} 2019$

\section{INTRODUCTION AND PRELIMINARIES}

In 1922, Banach proved the principal contraction result [4]. As we know, there have been published many works about fixed point theory for different kinds of contractions on some spaces such as quasi-metric spaces, cone metric spaces, convex metric spaces, partially ordered metric spaces, G-metric spaces, partial metric spaces, quasi-partial metric spaces, fuzzy metric spaces and Menger spaces.

The study of 2-metric spaces was initiated by Gahler[7] and some fixed point theorems in 2-metric spaces were proved in [8],[9], [10] and [15]. In 1987, Zeng [23] gave the generalization of 2-metric to Probabilistic 2metric as follows;

A probabilistic metric space shortly PM-Space, is an ordered pair (X, F) consisting of a non empty set $\mathrm{X}$ and a mapping $\mathrm{F}$ from $\mathrm{X} \times \mathrm{X}$ to $\mathrm{L}$, where $\mathrm{L}$ is the collection of all distribution functions (a distribution function $\mathrm{F}$ is non decreasing and left continuous mapping of reals in to $[0,1]$ with properties, $\inf \mathrm{F}(\mathrm{x})=0$ and $\sup \mathrm{F}(\mathrm{x})=1)$

1. The value of $F$ at $(x, y) \in X \times X$ is represented by $F_{x, y}$. The function $F_{x, y}$ are assumed satisfy the following conditions;

2. $(F M-0) F_{x, y}(t)=1$, for all $t>0$, iff $x=y$;

3. $(\mathrm{FM}-1) \mathrm{F}_{\mathrm{x}, \mathrm{y}}(0)=0$, if $\mathrm{t}=0$;

4. $(F M-2) F_{x, y}(t)=F_{y, x}(t)$;

5. $(\mathrm{FM}-3) \mathrm{F}_{\mathrm{x}, \mathrm{y}}(\mathrm{t})=1$ and $\mathrm{F}_{\mathrm{y}, \mathrm{z}}(\mathrm{s})=1$ then $\mathrm{F}_{\mathrm{x}, \mathrm{z}}(\mathrm{t}+\mathrm{s})=1$.

6. A mapping $\mathrm{T}:[0,1] \times[0,1] \rightarrow[0,1]$ is a t-norm, if it satisfies the following conditions;

7. $(\mathrm{FM}-4) \mathrm{T}(\mathrm{a}, 1)=\mathrm{a}$ for every $\mathrm{a} \in[0,1]$;

8. $(\mathrm{FM}-5) \mathrm{T}(0,0)=0$,

9. $(\mathrm{FM}-6) \mathrm{T}(\mathrm{a}, \mathrm{b})=\mathrm{T}(\mathrm{b}, \mathrm{a})$ for every $\mathrm{a}, \mathrm{b} \in[0,1]$;

10. $(F M-7) T(c, d) \geq T(a, b)$ for $c \geq a$ and $d \geq b$

11. $(F M-8) T(T(a, b), c)=T(a, T(b, c))$ where $a, b, c, d \in[0,1]$.

12. A Menger space is a triplet $(X, F, T)$, where $(X, F)$ is a PM-Space, $X$ is a non-empty set and a $t-$ norm satisfying instead of (FM-8) a stronger requirement.

13. (FM-9) $F_{x, z}(t+s) \geq T\left(F_{x, y}(t), F_{y, z}(s)\right)$ for all $x \geq 0, y \geq 0$.

14. For a given metric space $(X, d)$ with usual metric $d$, one can put $F_{x, y}(t)=H(t-d(x, y)$ ) for all $x, y \in$ $\mathrm{X}$ and $\mathrm{t}>0$. where $\mathrm{H}$ is defined as:

$$
H(t)=\left\{\begin{array}{l}
1 \text { if } s>0 \\
0 \text { if } s \leq 0
\end{array}\right.
$$

and $t$-norm $\mathrm{T}$ is defined as $\mathrm{T}(\mathrm{a}, \mathrm{b})=\min \{\mathrm{a}, \mathrm{b}\}$.

For the proof of our result we required the following definitions.

Definition 1.1 :-A triangular norm $*$ (shortly t-norm) is a binary operation on the unit interval $[0,1]$ such that for all $a, b, c, d \in[0,1]$ the following conditions are satisfied:

(1) $\mathrm{a} * 1=\mathrm{a}$,

(2) $\mathrm{a} * \mathrm{~b}=\mathrm{b} * \mathrm{a}$,

(3) a $*$ b $\leq$ c $*$ d whenever a $\leq$ c and b $\leq$ d, 
(4) $\mathrm{a} *(\mathrm{~b} * \mathrm{c})=(\mathrm{a} * \mathrm{~b}) * \mathrm{c}$.

Examples of t-norms are $\mathrm{a} * \mathrm{~b}=\min \{\mathrm{a}, \mathrm{b}\}, \mathrm{a} * \mathrm{~b}=\mathrm{ab}$ and $\mathrm{a} * \mathrm{~b}=\max \{\mathrm{a}+\mathrm{b}-1,0\}$.

Definition 1.2 :- Let $(X, F, *)$ be a Menger space and $*$ be a continuous t-norm.

(a) A sequence $\left\{x_{n}\right\}$ in $X$ is said to be converge to a point $x$ in $X$ (written $x_{n} \rightarrow x$ ) iff for every $\varepsilon>0$ and $\lambda \in$ $(0,1)$, there exists an integer $\mathrm{n}_{0}=\mathrm{n}_{0}(\varepsilon, \lambda)$ such that $\mathrm{F}_{\mathrm{x}_{\mathrm{n}} \mathrm{x}}(\varepsilon)>1-\lambda$ for all $\mathrm{n} \geq \mathrm{n}_{0}$.

(b) A sequence $\left\{x_{n}\right\}$ in $X$ is said to be Cauchy if for every $\varepsilon>0$ and $\lambda \in(0,1)$, there exists an integer $n_{0}=$ $\mathrm{n}_{0}(\varepsilon, \lambda)$ such that $\mathrm{F}_{\mathrm{x}_{\mathrm{n}, \mathrm{x}_{\mathrm{n}} \mathrm{p}}}(\varepsilon)>1-\lambda$ for all $\mathrm{n} \geq \mathrm{n}_{0}$ and $\mathrm{p}>0$.

(c) A Menger space in which every Cauchy sequence is convergent is said to be complete.

Remark 1.3:- If is a continuous t-norm, it follows from $(F M-4)$ that the limit of sequence in Menger space is uniquely determined.

Definition 1.4:- Self maps A and B of a Menger space $(X, F, *)$ are said to be weakly compatible (or coincidentally commuting) if they commute at their coincidence points, i.e. if $\mathrm{Ax}=\mathrm{Bx}$ for some $\mathrm{x} \in \mathrm{X}$ then $\mathrm{ABx}=\mathrm{BAx}$.

\section{Weakly Compatible Maps}

In 1982, Sessa [17], weakened the concept of commutativity to weakly commuting mappings. Afterwards, Jungck [4] enlarged the concept of weakly commuting mappings by adding the notion of compatible mappings. In 1991, Mishra [16] introduced the notion of compatible mappings in the setting of probabilistic metric space.

Definition 1.5 :- Self maps $A$ and $B$ of a Menger space $(X, F, *)$ are said to be compatible if $F_{A_{B x} B_{A x}}(t) \rightarrow 1$ for all $t>0$, whenever $\left\{\mathrm{x}_{\mathrm{n}}\right\}$ is a sequence in $\mathrm{X}$ such that $\mathrm{Ax}_{\mathrm{n}} \rightarrow \mathrm{x}, \mathrm{Bx} \mathrm{n} \rightarrow \mathrm{x}$ for some $\mathrm{x}$ in $\mathrm{X}$ as $\mathrm{n} \rightarrow \infty$.

Definition 1.6:- Let $S$ and $T$ be weakly compatible of a Menger space $(X, M, *)$ and $S u=T u$ for some $u$ in $\mathrm{X}$ then

$$
\mathrm{STu}=\mathrm{TSu}=\mathrm{SSu}=\mathrm{TTu} .
$$

Definition 1.7:- (Implicit Relation) Let $\phi_{4}$ be the set of real and continuous function from $\left(R^{+}\right)^{4} \rightarrow R$ so that

(i) $\phi$ is non-increasing in $2^{\text {nd }}, 3^{\text {rd }}$ argument and

(ii) For $u, v \geq 0 \phi(u, v, v, v) \geq 0 \Rightarrow u \geq v$

Example 1.8:- Let $X=[0,3]$ be equipped with the usual metric $d(x, y)=|x-y|$ Define $f, g:[0,3] \rightarrow[0,3]$ by

And

$$
\begin{aligned}
& f(x)=\left\{\begin{array}{l}
x \text { if } x \in[0,1), \\
3 \text { if } x \in[1,3] .
\end{array}\right. \\
& g(x)=\left\{\begin{array}{rr}
3-x \text { if } x \in[0,1), \\
3 \text { if } x \in[1,3] .
\end{array}\right.
\end{aligned}
$$

Then for any $\mathrm{x} \in[1,3], \mathrm{x}$ is a coincidence point and fgx $=$ gfx, showing that $\mathrm{f}, \mathrm{g}$ are weakly compatible maps on $[0,3]$.

Lemma 1.9:- Let $(X, M, *)$ be a Menger space. Then for all $x, y \in X, M(x, y,$.$) is a non-decreasing function.$

Lemma 1.10:- Let $(X, M, *)$ be a Menger space. If there exists $k \in(0,1)$ such that

for all $\mathrm{x}, \mathrm{y} \in \mathrm{X}$

then $\mathrm{x}=\mathrm{y}$.

$$
\mathrm{M}_{\mathrm{x}, \mathrm{y}}(\mathrm{t}) \geq \mathrm{M}_{\mathrm{x}, \mathrm{y}}(\mathrm{t}) \quad \forall \mathrm{t}>0
$$

Lemma 1.11:- Let $\left\{x_{n}\right\}$ be a sequence in a Menger space $(X, M, *)$. If there exists a number $k \in(0,1)$ such that Then $\left\{\mathrm{x}_{\mathrm{n}}\right\}$ is a Cauchy sequence in $\mathrm{X}$.

$$
\mathrm{M}_{\mathrm{x}_{\mathrm{n}+2, \mathrm{x}_{\mathrm{n}+1}}}(\mathrm{kt}) \geq \mathrm{M}_{\mathrm{x}_{\mathrm{n}+1}, \mathrm{x}_{\mathrm{n}}}(\mathrm{t}) \forall \mathrm{t}>0 \text { and } \mathrm{n} \in \mathrm{N} \text {. }
$$

Lemma 1.12:- The only t-norm $*$ satisfying $r * r \geq r$ for all $r \in[0,1]$ is the minimum $t$-norm, that is $\mathrm{a} * \mathrm{~b}=\min \{\mathrm{a}, \mathrm{b}\}$ for all $\mathrm{a}, \mathrm{b} \in[0,1]$.

Lemma 1.13:- Let $(X, M, *)$ be a Menger space and $\forall x, y \in X, t>0$ and if for a number $k \in(0,1)$, $M(x, y, k t) \geq M(x, y, t)$ then $x=y$.

Example 1.14:- Let $(X, d)$ be a metric space. Define $a * b=\min \{a, b\}$ and $M_{x, y}(t)=\frac{t}{t+d(x, y)}$, for all $x, y \in X$.and all $t>0$. Then $(X, M, *)$ is a Menger space. It is called the Menger space induced by $\mathrm{d}$.

Remark 1.15:- If self maps A and B of a Menger space $(\mathrm{X}, \mathrm{F}, *)$ are compatible then they are weakly compatible.

\section{MAIN RESULT}

Now we prove the following results:

Theorem 2.1: Let $(X, M, *)$ be a common fixed point theorem in 2- Menger space with compatible maps. Let 
$A, B, S$ and $T$ be mappings of $X$ into itself satisfying following conditions:

(2.1) $A X \subset T X$ and $B X \subset S X$

(2.2) $\{A, S\}$ or $\{B, T\}$ satisfy the (S-B) property

(2.3) there exists a constant $q \in(0,1)$ such that $\mathrm{x}, \mathrm{y}, \mathrm{a} \in \mathrm{X}$ and $\mathrm{t}>0$,

$$
\alpha\left(\mathrm{M}_{\mathrm{Ax}, \mathrm{By}, \mathrm{a}}(\mathrm{qt}) * \frac{\mathrm{M}_{\mathrm{Sx}, \mathrm{Ty}, \mathrm{a}}(\mathrm{t})+\mathrm{M}_{\mathrm{Ax}, \mathrm{Sx}, \mathrm{a}}(\mathrm{t})}{2} * \frac{\mathrm{M}_{\mathrm{By}, \mathrm{Ty}, \mathrm{a}}(\mathrm{t})+\mathrm{M}_{\mathrm{Ax}, \mathrm{Ty}, \mathrm{a}}(\mathrm{t})}{2}\right) \geq 0
$$

(2.4) If the pairs $\{A, S\}$ or $\{B, T\}$ are weakly compatible

(2.5) One of $\mathrm{A}(\mathrm{X}), \mathrm{B}(\mathrm{X}), \mathrm{S}(\mathrm{X})$ or $\mathrm{T}(\mathrm{X})$ is closed subset of $X$.

Indeed, $A, B, S$ and $T$ have a unique common fixed point in $X$.

Proof. Suppose that $\{B, T\}$ satisfies the (S-B) property. Then there exists a sequence $\left\{x_{n}\right\}$ in $X$ such that $\lim _{n \rightarrow \infty} B x_{n}=\lim _{n \rightarrow \infty} T x_{n}=z$ for some $z \in X$.

Since $B X \subset S X$, there exists in $X$ a sequence $\left\{y_{n}\right\}$ such that $B x_{n}=S y_{n}$.

Hence $\lim _{n \rightarrow \infty} S x_{n}=z$.

Let us show that $\lim _{n \rightarrow \infty} A y_{n}=z$.

Now by equation (2.1.1), we have

$$
\begin{aligned}
& \alpha\left(M_{A y_{n}, B x_{n}, a}(q t) * \frac{M_{S_{n}, T x_{n}, a}(t)+M_{A y_{n}, S y_{n}, a}(t)}{2} * \frac{M_{B x_{n}, T x_{n}, a}(t)+M_{A y_{n}, T x_{n}, a}(t)}{2}\right) \geq 0 \\
& \alpha\left(M_{A y_{n}, B x_{n}, a}(q t) * \frac{M_{B x_{n}, T x_{n}, a}(t)+M_{A y_{n}, B x_{n}, a}(t)}{2} * \frac{M_{B x_{n}, T x_{n}, a}(t)+M_{A y_{n}, T x_{n}, a}(t)}{2}\right) \geq 0
\end{aligned}
$$

Since $\lim _{n \rightarrow \infty} B x_{n}=\lim _{n \rightarrow \infty} T x_{n}$

$\therefore M\left(B x_{n}, T x_{n}, t\right)=1$

So taking $\lim n \rightarrow \infty$

$$
\alpha\left(\mathrm{M}_{\mathrm{Ay}_{\mathrm{n}}, \mathrm{Bx}_{\mathrm{n}}, \mathrm{a}}(\mathrm{qt}) * \frac{1+\mathrm{M}_{\mathrm{Ay}_{\mathrm{n}}, \mathrm{Bx}_{\mathrm{n}}, \mathrm{a}}(\mathrm{t})}{2} * \frac{1+\mathrm{M}_{\mathrm{Ay}_{\mathrm{n}}, \mathrm{Bx}_{\mathrm{n}}, \mathrm{a}}(\mathrm{t})}{2}\right) \geq 0
$$

$\phi$ is non-increasing in $2^{\text {nd }}, 3^{\text {rd }}$ argument

By the definition (1.7)

$$
\alpha\left(M_{{A y_{n}, B x_{n}, a}}(q t) * M_{A y_{n}, B x_{n}, a}(t) * M_{A y_{n}, B x_{n}, a}(t)\right) \geq 0
$$

Since $M$ is continuous function

$$
M_{A y_{n}, B x_{n}, a}(q t) \geq M_{A y_{n}, B x_{n}, a}(t)
$$

By lemma (1.13)

$$
\lim _{n \rightarrow \infty} M_{A y_{n}, B x_{n}, a}(q t) \geq \lim _{n \rightarrow \infty} M_{A y_{n}, B x_{n}, a}(t)
$$

$\lim _{n \rightarrow \infty} A y_{n}=\lim _{n \rightarrow \infty} B x_{n}$ and we deduce that

$\lim _{n \rightarrow \infty} A y_{n}=z$

Suppose $S X$ is a closed subset of $X$.

Then $z=S u$ for some $u \in X$.

Subsequently we have,

$\lim _{n \rightarrow \infty} A y_{n}=\lim _{n \rightarrow \infty} B x_{n}=\lim _{n \rightarrow \infty} T x_{n}=\lim _{n \rightarrow \infty} S y_{n}=S u$.

By (2.3), we have

$$
\alpha\left(M_{A u, B x_{n}, a}(q t) * \frac{M_{S u, T x_{n}, a}(t)+M_{A u, S u, a}(t)}{2} * \frac{M_{B x_{n}, T x_{n}, a}(t)+M_{A u, T x_{n}, a}(t)}{2}\right) \geq 0
$$




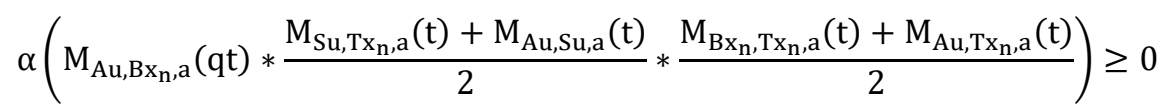

Taking $\lim n \rightarrow \infty$, we have

$\phi$ is non-increasing in $2^{\text {nd }}, 3^{\text {rd }}$ argument

$$
\begin{gathered}
\alpha\left(\mathrm{M}_{\mathrm{Au}, \mathrm{Su}, \mathrm{a}}(\mathrm{qt}) * \frac{\mathrm{M}_{\mathrm{Su}, \mathrm{Su}, \mathrm{a}}(\mathrm{t})+\mathrm{M}_{\mathrm{Au}, \mathrm{Su}, \mathrm{a}}(\mathrm{t})}{2} * \frac{\mathrm{M}_{\mathrm{Su}, \mathrm{Su}, \mathrm{a}}(\mathrm{t})+\mathrm{M}_{\mathrm{Au}, \mathrm{Su}, \mathrm{a}}(\mathrm{t})}{2}\right) \geq 0 \\
\alpha\left(\mathrm{M}_{\mathrm{Au}, \mathrm{Su}, \mathrm{a}}(\mathrm{qt}) * \frac{1+\mathrm{M}_{\mathrm{Au}, \mathrm{Su}, \mathrm{a}}(\mathrm{t})}{2} * \frac{1+\mathrm{M}_{\mathrm{Au}, \mathrm{Su}, \mathrm{a}}(\mathrm{t})}{2}\right) \geq 0
\end{gathered}
$$

By the definition (1.7)

$$
\alpha\left(\mathrm{M}_{\mathrm{Au}, \mathrm{Su}, \mathrm{a}}(\mathrm{qt}) * \mathrm{M}_{\mathrm{Au}, \mathrm{Su}, \mathrm{a}}(\mathrm{t}) * \mathrm{M}_{\mathrm{Au}, \mathrm{Su}, \mathrm{a}}(\mathrm{t})\right) \geq 0
$$

Thus by lemma (1.13)

$$
M_{A u, S u, a}(q t) \geq M_{A u, S u, a}(t)
$$

We have $A u=S u$.

The weak compatibility of $A$ and $S$ implies that $A S u=S A u$ and then $A A u=A S u=S A u=S S u$.

On the other hand,

Since $A X \subseteq T X$, there exists a point $v \in X$ such that $A u=T v$. We claim that $A u=B v$ using (2.3); we have

$$
\begin{aligned}
\alpha\left(M_{A u, B v, a}(q t)\right. & \left.* \frac{M_{S u, T v, a}(t)+M_{A u, S u, a}(t)}{2} * \frac{M_{B v, T v, a}(t)+M_{A u, T v, a}(t)}{2}\right) \geq 0 \\
\alpha\left(M_{A u, B v, a}(q t)\right. & \left.* \frac{M_{S u, A u, a}(t)+M_{A u, S u, a}(t)}{2} * \frac{M_{B v, A u, a}(t)+M_{A u, A u, a}(t)}{2}\right) \geq 0 \\
\alpha\left(M_{A u, B v, a}(q t) * 1 * \frac{1+M_{A u, B v, a}(t)}{2}\right) \geq 0 &
\end{aligned}
$$

$\phi$ is non-increasing in $2^{\text {nd }}, 3^{\text {rd }}$ argument

By the definition (1.7)

$$
\alpha\left(\mathrm{M}_{\mathrm{Au}, \mathrm{Bv}, \mathrm{a}}(\mathrm{qt}) * \mathrm{M}_{\mathrm{Au}, \mathrm{Bv}, \mathrm{a}}(\mathrm{t}) * \mathrm{M}_{\mathrm{Au}, \mathrm{Bv}, \mathrm{a}}(\mathrm{t})\right) \geq 0
$$

Therefore by lemma, we have

$$
M_{A u, B v, a}(t) \geq M_{A u, B v, a}(t)
$$

$A u=B v$

Thus $A u=S u=T v=B v$.

The weak compatibility of $B$ and T implies that $B T v=T B v$ and $T T v=T B v=B T v=B B v$.

Let us show that $A u$ is a common fixed point of $A, B, S$ and $T$.

In view of (2.3) we have

$$
\begin{gathered}
\alpha\left(\mathrm{M}_{\mathrm{AAu}, \mathrm{Bv}, \mathrm{a}}(\mathrm{qt}) * \frac{\mathrm{M}_{\mathrm{SAu}, \mathrm{Tv}, \mathrm{a}}(\mathrm{t})+\mathrm{M}_{\mathrm{AAu}, \mathrm{SAu}, \mathrm{a}}(\mathrm{t})}{2} * \frac{\mathrm{M}_{\mathrm{Bv}, \mathrm{Tv}, \mathrm{a}}(\mathrm{t})+\mathrm{M}_{\mathrm{AAu}, \mathrm{Tv}, \mathrm{a}}(\mathrm{t})}{2}\right) \geq 0 \\
\alpha\left(\mathrm{M}_{\mathrm{AAu}, \mathrm{Au}, \mathrm{a}}(\mathrm{qt}) * \frac{\mathrm{M}_{\mathrm{AAu}, \mathrm{Au}, \mathrm{a}}(\mathrm{t})+\mathrm{M}_{\mathrm{AAu}, \mathrm{AAu}, \mathrm{a}}(\mathrm{t})}{2} * \frac{\mathrm{M}_{\mathrm{Au}, \mathrm{Au}, \mathrm{a}}(\mathrm{t})+\mathrm{M}_{\mathrm{AAu}, \mathrm{Au}, \mathrm{a}}(\mathrm{t})}{2}\right) \geq 0 \\
\alpha\left(\mathrm{M}_{\mathrm{AAu}, \mathrm{Au}, \mathrm{a}}(\mathrm{qt}) * \frac{1+\mathrm{M}_{\mathrm{AAu}, \mathrm{Au}, \mathrm{a}}(\mathrm{t})}{2} * \frac{1+\mathrm{M}_{\mathrm{AAu}, \mathrm{Au}, \mathrm{a}}(\mathrm{t})}{2}\right) \geq 0
\end{gathered}
$$

$\phi$ is non-increasing in $2^{\text {nd }}, 3^{\text {rd }}$ argument

By the definition (1.7)

$$
\alpha\left(\mathrm{M}_{\mathrm{AAu}, \mathrm{Au}, \mathrm{a}}(\mathrm{qt}) * \mathrm{M}_{\mathrm{AAu}, \mathrm{Au}, \mathrm{a}}(\mathrm{t}) * \mathrm{M}_{\mathrm{AAu}, \mathrm{Au}, \mathrm{a}}(\mathrm{t})\right) \geq 0
$$

Therefore by lemma, we have

$$
M_{A A u, A u, a}(q t) \geq M_{A A u, A u, a}(t)
$$

$A u=A A u=S A u$ and $A u$ is a common fixed point of $A$ and $S$.

Similarly, we can validate that $B v$ is a common fixed point of $B$ and $T$.

Since $A u=B v$, we achieve that $A u$ is point of $A, B, S$ and $T$, 
which is called common fixed point.

If $A u=B u=S u=T u=u$ and $A v=B v=S v=T v=v$.

Then by (2.3), we have

$$
\begin{gathered}
\alpha\left(\mathrm{M}_{\mathrm{Au}, \mathrm{Bv}, \mathrm{a}}(\mathrm{qt}) * \frac{\mathrm{M}_{\mathrm{Su}, \mathrm{Tv}, \mathrm{a}}(\mathrm{t})+\mathrm{M}_{\mathrm{Au}, \mathrm{Su}, \mathrm{a}}(\mathrm{t})}{2} * \frac{\mathrm{M}_{\mathrm{Bv}, \mathrm{Tv}, \mathrm{a}}(\mathrm{t})+\mathrm{M}_{\mathrm{Au}, \mathrm{Tv}, \mathrm{a}}(\mathrm{t})}{2}\right) \geq 0 \\
\alpha\left(\mathrm{M}_{\mathrm{u}, \mathrm{v}, \mathrm{a}}(\mathrm{qt}) * \frac{\mathrm{M}_{\mathrm{u}, \mathrm{v}, \mathrm{a}}(\mathrm{t})+\mathrm{M}_{\mathrm{u}, \mathrm{u}, \mathrm{a}}(\mathrm{t})}{2} * \frac{\mathrm{M}_{\mathrm{v}, \mathrm{v}, \mathrm{a}}(\mathrm{t})+\mathrm{M}_{\mathrm{u}, \mathrm{v}, \mathrm{a}}(\mathrm{t})}{2}\right) \geq 0 \\
\alpha\left(\mathrm{M}_{\mathrm{u}, \mathrm{v}, \mathrm{a}}(\mathrm{qt}) * \frac{1+\mathrm{M}_{\mathrm{u}, \mathrm{v}, \mathrm{a}}(\mathrm{t})}{2} * \frac{1+\mathrm{M}_{\mathrm{u}, \mathrm{v}, \mathrm{a}}(\mathrm{t})}{2}\right) \geq 0
\end{gathered}
$$

$\phi$ is non-increasing in $2^{\text {nd }}, 3^{\text {rd }}$ argument

By the definition (1.7)

$$
\alpha\left(\mathrm{M}_{\mathrm{u}, \mathrm{v}, \mathrm{a}}(\mathrm{qt}) * \mathrm{M}_{\mathrm{u}, \mathrm{v}, \mathrm{a}}(\mathrm{t}) * \mathrm{M}_{\mathrm{u}, \mathrm{v}, \mathrm{a}}(\mathrm{t})\right) \geq 0
$$

$$
\mathrm{M}_{\mathrm{u}, \mathrm{v}, \mathrm{a}}(\mathrm{t}) \geq \mathrm{M}_{\mathrm{u}, \mathrm{v}, \mathrm{a}}(\mathrm{t})
$$

Therefore by lemma, we have $u=v$ and the common fixed point is a unique.

This explanation is verified the theorem. Hence $A, B, S$ and $T$ have a unique common fixed point in $X$.

\section{References}

1. Aydi H., Karapınar, E., Postolache, M: Tripled coincidence point theorems for weak $\phi$-contractions in partially ordered metric spaces. Fixed Point Theory Appl. 2012, 44 (2012).

2. Aydi, H, Postolache, M, Shatanawi, W: Coupled fixed point results for $(\psi, \varphi)$-weakly contractive mappings in ordered G-metric spaces. Comput. Math. Appl. 63(1), 298-309 (2012).

3. Aydi, H: Fixed point results for weakly contractive mappings in ordered partial metric spaces. J. Adv. Math. Stud. 4(2), 1-12 (2011).

4. Banach, S.," Sur les operations dans les ensembles abstraits et leur application aux equations" integrales. Fundam. Math. 3, 133-181, (1922).

5. Chandok, S, Mustafa, Z, Postolache, M: Coupled common fixed point theorems for mixed g-monotone mappings in partially ordered G-metric spaces. U. Politeh. Buch. Ser. A 75(4), 11-24 (2013).

6. Choudhury B. S. Metiya N.," Coincidence point and fixed point theorems in ordered cone metric spaces". J. Adv. Math. Stud. 5(2), 20-31, (2012).

7. Gahler S., "2-metrische Raume und ihre topologische Struktur" Math., Nachr., 26, 115-148, (1963).

8. Hadzic, O.," On common fixed point theorems in 2-metric Spaces" Univ. Novom Sadu Zb. Rad. Prirod. Mat. Fak. Mat. 12, 7-18, (1982).

9. Hicks T. L.,"Fixed point theorems for quasi-metric spaces" Math. Jpn. 33(2), 231-236, (1988).

10. Iseki K. "Fixed point theorem in 2-metric spaces" Math. Sem. Notes. Kobe Uni. 3, 133-136, (1975).

11. Kutukcu, S: A fixed point theorem in Menger spaces. Int. Math. Forum 1(32), 1543-1554, (2006).

12. Menger, K: Statistical metrics. Proc. Natl. Acad. Sci. USA 28, 535-537 (1942).

13. Olatinwo M.O, Postolache, M.," Stability results for Jungck-type iterative processes in convex metric spaces". Appl. Math. Comput. 218(12), 6727-6732, (2012).

14. Pant, BD, Chauhan, S: Common fixed point theorems for two pairs of weakly compatible mappings in Menger spaces and fuzzy metric spaces. Sci. Stud. Res. Ser. Math. Inform. 21(2), 81-96, (2011).

15. Roades B.E., "Contraction type mapping on 2-metric spaces" Math. Nachr. 91, 151-155, (1979).

16. Sharma S., Bamboria D.,"Some new common fixed point theorems in fuzzy metric space under strict contractive conditions"J. Fuzzy Math., 14(2), 1-11, (2006).

17. Shatanawi, W, Pitea, A: Fixed and coupled fixed point theorems of omega-distance for nonlinear contraction. Fixed Point Theory Appl. 2013, 275 (2013).

18. Shatanawi, W, Pitea, A: Omega-distance and coupled fixed point in G-metric spaces. Fixed Point Theory Appl. 2013, 208 (2013).

19. Shatanawi, W, Postolache, M: Coincidence and fixed point results for generalized weak contractions in the sense of Berinde on partial metric spaces. Fixed Point Theory Appl., 54, (2013).

20. Shatanawi, W, Postolache, M: Common fixed point results of mappings for nonlinear contractions of cyclic form in ordered metric spaces. Fixed Point Theory Appl. 2013, 60 (2013).

21. Shatanawi, W, Postolache, M: Some fixed point results for a G-weak contraction in G-metric spaces. Abstr. Appl. Anal. 2012, Article ID 815870 (2012).

22. Z. K. Deng” Fuzzy Pseudo Metric Spaces” J. Math. Anal. Appl., 86, 74-95, (1982). 
23. Zeng Wenzhi” Probabilistic 2- metric Spaces” J. Math. Research Expo. 2, 241-245, (1987). 